\section{Detection of Root Canal Isthmuses in Molars by Map-Reading Dynamic using CBCT images}

Jesus Djalma Pécora', Carlos Estrela², Mike Reis Bueno², Olavo César Porto², Ana Helena Gonçalves Alencar², Manoel Damião Sousa-Neto', Cyntia Rodrigues de Araújo Estrela²

The aim of this study was to detect root isthmuses in maxillary and mandibular molars and evaluate their frequencies using map-reading dynamics in CBCT images. Two hundred extracted human maxillary and mandibular molars were used in ex vivo assay. A consecutive sample of two hundred maxillary and mandibular molars (first and second) was selected from CBCT exams. The isthmuses were detected from the pulp orifice to the apex and were recorded according to their beginning and their end, into categories: 1 . begin and end in cervical third; 2 . beginning in cervical third and end in middle third; 3 . beginning in cervical third and end in apical third; 4 . beginning and end in middle third; 5 . begin in middle third and end in apical third; 6 . beginning and end in apical third; 7 . no isthmus. The scans were obtained in different planes with map-reading in axial slices of $0.5 \mathrm{~mm} / 0.5$ $\mathrm{mm}$ involved the coronal to apical direction. The frequencies of isthmus were analyzed according to the level of root and evaluated by Chi-square test. The level of significance was set at $\alpha=0.05$. The presence of isthmus detected in maxillary molars was $86 \%$ in ex vivo assay and $62 \%$ in vivo assay, whereas in mandibular molars was observed $70 \%$ in ex vivo assay and $72 \%$ in vivo assay. The frequency of isthmus was high in both study models. The map-reading dynamics in CBCT images was found to be precise to detect the localization of isthmus.

\author{
'Department of Restorative \\ Dentistry, Ribeirão Preto School of \\ Dentistry, USP - University of São \\ Paulo, Ribeirão Preto, SP, Brazil \\ ${ }^{2}$ Department of Stomatologic \\ Sciences, School of Dentistry, \\ UFG - Federal University of \\ Goiás, Goiânia, GO, Brazil
}

Correspondence: Prof. Dr. Jesus Djalma Pécora, Avenida do Café, S/N, Monte Alegre, 14040-904 Ribeirão Preto, SP, Brasil. Tel: +55-16-36023982. Fax: +55-16-3633-0999. e-mail: pecora@forp.usp.br

\section{Introduction}

The mysterious shapes that characterize the root canal internal anatomy have been exhaustively studied (1-5). In recent years, there has been increased interest on root isthmus area (6-10), and its influence on the root canal treatment (RCT).

The isthmus may be considered as a narrow extension from either one or two main root canals, subdivided in incomplete or complete (5-7). Weller et al. (5) verified a prevalence of this anatomical structure ranging from 12\% to $88 \%$ in the 4-mm-thick sections, contained a complete or a partial isthmus, respectively. During some years the isthmus remained overlooked. It was difficult to locate and to prepare. Hsu and Kim (6) classified the isthmus in 5 types: 1: two or three root canals with no notable communication; 2: two root canals with definite connection between the two main root canals; 3 : the presence of three root canals instead of two; incomplete $\mathrm{C}$-shaped canals with three canals; 4 : canals extending to the isthmus; 5 : a true connection or corridor throughout the section.

To prepare and seal a root canal, correctly and completely, is the daily challenge of the endodontist. The expectative of life of an endodontically treated tooth is to maintaining free of the disease. The success always is the outcome most expected after a RCT independently of the clinical condition, vital or infected pulp. RCT is characterized by emptying and enlarging the root canal, removing organic and infected tissue, microorganisms and their byproducts, filled the canal space and tightly sealing the coronal access (11). Nair et al. (12) assessed intracanal microbial status of apical root canal system of mesial roots of human mandibular first molars with primary apical periodontitis immediately after one-visit endodontic treatment. The results of this study showed that anatomical complexity of the root canal system of mandibular first molar roots and the organization of the flora as biofilms in inaccessible areas of the canal system that cannot be accessed by contemporary instruments and irrigation alone in one-visit treatment. These findings demonstrate the importance of stringent application of all nonantibiotic chemomechanical measures to treat teeth with infected and necrotic root canals so as to disrupt the biofilms and reduce the intraradicular microbial load to the lowest possible level so as to expect a highly favorable long-term prognosis of the root canal treatment.

In an attempt to overcome the difficulties found during the RCT especially against sanitizing and shaping process of complex anatomical, different invasive and non-invasive methods have been used to observe inside root canals 
(1-10), including: radiographic, vertical and transversal sectioning, decalcified and dyed, stereomicroscope, surgical microscope, dissecting microscope, plastic casts, scanning electron microscope.

Periapical radiography (PR) is the most widely used imaging method used during RCT. However, the limitations and implications of RCT outcomes based on periapical radiography are known (13-15). It might be illusory to evaluate the three-dimensional macroconfiguration of the root canal system by an imaging examination that shows the anatomical structures in only two dimensions (14). Therefore, new technological resources have been incorporated to endodontic research to aid in the study of internal root canal anatomy, such as cone beam computed tomography (CBCT) and micro-computed tomography $(\mu \mathrm{CT})$ (14-25).

Considering the role of isthmuses on RCT and the impossibility to have access in most cases, the use of $\mathrm{CBCT}$ could contribute to their location. Thus, the aims of this study were to detect the longitudinal isthmus location in maxillary and mandibular molars, and to evaluate their frequencies using map-reading dynamics in CBCT images.

\section{Material and Methods}

\section{Ex Vivo Assay}

The sample consisted of 200 extracted human molars. The age, gender and race of the donors were unknown. The teeth were stored in $0.2 \%$ thymol solution and then immersed in $5 \% \mathrm{NaOCl}$ for $30 \mathrm{~min}$ to remove external organic tissues.

Preoperative radiographs of each tooth were taken to confirm the absence of calcified root canals and internal and external resorption, and the presence of a fully formed apex. Only the mesiobuccal root of maxillary molars and mesial of mandibular molars were used. In this ex vivo assay was considered maxillary and mandibular molars, without differentiation between the first and second. All teeth were shorter than $23 \mathrm{~mm}$. The study design was approved by the institutional Ethics Committee.

CBCT images were obtained using a PreXion 3D Inc. (San Mateo, CA, USA), thickness: $0.100 \mathrm{~mm}$ (dimensions $1,170 \times 1,570 \times 1,925 \mathrm{~mm}$, FOV: $56.00 \mathrm{~mm}$, voxel 0.100 $\mathrm{mm}, 33.5 \mathrm{sec}$. (1,024 views). Tube voltage was $90 \mathrm{kVp}$, and the tube current was $4 \mathrm{~mA}$. Exposure time was 33.5 s. Images were examined with the scanner's proprietary software PreXion 3D Viewer (TeraRecon Inc, Foster City, Ca, USA) in a PC workstation running Windows XP professional SP-2 (Microsoft Corp., Redmond, WA, USA), with processor Intel Core 2 Duo-6300 1.86 Ghz (Intel Corp., Santa Clara, CA, USA), NVIDIA GeForce 6200 turbo cache videocard (NVIDIA Corporation, Santa Clara, CA, USA), and Monitor EIZO-Flexscan S2000, resolution 1600X1200 pixels (EIZO NANAO Corp., Hakusan, Japan).

\section{In Vivo Assay}

The study was structured using databases of private radiology clinics (CIRO, Goiânia, GO, Brazil). The patients were referred to the dental radiology service for different diagnostic purposes. A consecutive sample of two hundred maxillary and mandibular molars (first and second) was selected from CBCT exams of 171 patients (73 men and 98 women; mean age $=38.98$ years) between November 2012 and October 2013. CBCT exams of maxillary and mandibular first and second molars, without previous endodontic treatment, post and crowns, with the absence of calcified root canals or internal/external root resorption, and the presence of a fully formed apex were included in the study. In addition, only images with high-resolution quality that permitted an accurate analysis were considered.

\section{Isthmus Detection}

The presence or absence of root canal isthmus in each tooth (ex vivo and in vivo) was analyzed from the pulp orifice to the apex and was recorded according to its beginning and end, into 7 categories: 1. beginning and ending in cervical third (CT-CT); 2. beginning in cervical third and ending in middle third (CT-MT); 3 . beginning in cervical third and ending in apical third (CT-AT); 4. beginning and end in middle third (MT-MT); 5 . beginning in middle third and ending in apical third (MT-AT); 6. beginning and ending in apical third (AT-AT); 7. no isthmus.

The involved tooth was focused, and scans were viewed in different planes (sagittal, coronal, and axial) of $0.5-\mathrm{mm}$ thickness. Navigation in axial slices of $0.5 \mathrm{~mm} / 0.5 \mathrm{~mm}$ involved the coronal to apical direction (and also the apical to coronal direction). This map-reading provided valuable information for better visualization and identification of frequency and position of isthmus. All imaging exams were analyzed by 2 observers (one endodontist and one radiologist, both with 10 or more years of experience), which were calibrated by using $10 \%$ of the sample; when differences were observed, a consensus was reached, discussing the image by third observer.

\section{Statistical Analysis}

The frequency distribution of the different types of isthmus was analyzed according to the level of root and evaluated by the chi-square test. Significance level was set at $\alpha=0.05$. Statistical analysis of data was performed using the Statistical Package for Social Sciences, version 20 (SPSS, Chicago, IL, USA).

\section{Results}

The presence of isthmus detected in maxillary molars was $86 \%$ in the ex vivo assay and $62 \%$ in the in vivo assay, whereas in mandibular molars was observed $70 \%$ in the ex 
vivo assay and $72 \%$ in the in vivo assay. When the isthmus began at the middle third and end at the apical third ranged from $48 \%$ for mandibular molars and $32 \%$ for the maxillary molars in the ex vivo assay; whereas for the in vivo assay was observed $45 \%$ for the mandibular molars and 25\% for maxillary molars (Tables 1 and 2).

In the ex vivo assay, the presence of isthmus in maxillary molars showed a significant difference $(p<0.05)$ between the cervical third and apical third, and between the middle third and apical third. Presence of isthmus in the cervical and middle thirds showed no statistically significant difference ( $p>0.05$ ) (Table 1).

In the in vivo assay, 26 mandibular teeth (26\%) had root canal isthmus beginning and ending in the apical third, and only 2 teeth $(2 \%)$ had root canal isthmus beginning and ending in the middle third. Thirty-eight maxillary molars $(38 \%)$ had no isthmus. From a total of 100 mandibular and 100 maxillary molars, $38 \%$ of mandibular molars and $30 \%$ of maxillary molars had two foramina. Significant correlation was observed $(p<0.05)$ between the presence or absence of the root canal isthmus and the number of apical foramina in the first and second mandibular molars, while for the first and second maxillary molars no significant differences were found. No significant correlation was observed between the root canal isthmus (cervical, middle and apical thirds) and the number of apical foramina for first and second mandibular and maxillary molars ( $>0.05$ ) (Table 2).

Figures 1 and 2 show coronal and axial slices of isthmus in maxillary and mandibular molars from ex vivo and in vivo images. Figures 3-5 show three cases with CBCT images, in mandibular molars endodontically treated and associated with apical periodontitis. In the longitudinal map-reading highlights isthmus areas not prepared and nor filled.

\section{Discussion}

The isthmuses were well visualized by longitudinal map-reading dynamic from pulp orifice to the apex in CBCT images. The CBCT study method allowed identification in both ex vivo and in vivo images. The use of $\mathrm{CBCT}$ images enhances its precision as it allows a longitudinal location, beyond to represent a noninvasive methodology. The presence of isthmus occurred in high frequency on teeth

Table 1. Distribution of root canal isthmus in the ex vivo assay in function of its location and number of foramens

\begin{tabular}{|c|c|c|c|c|c|c|c|c|c|}
\hline Teeth & CT-CT & CT-MT & CT-AT & MT-MT & MT-AT & AT-AT & No isthmus & 1 foramen & 2 foramen \\
\hline $\begin{array}{l}\text { Maxillary molars } \\
(n=100)\end{array}$ & $9(9 \%)$ & $35(35 \%)$ & $16(16 \%)$ & $16(16 \%)$ & $12(12 \%)$ & $4(4 \%)$ & $14(14 \%)$ & $47(47 \%)$ & $53(53 \%)$ \\
\hline $\begin{array}{l}\text { Mandibular } \\
\text { molars }(n=100)\end{array}$ & $15(15 \%)$ & $4(4 \%)$ & $7(7 \%)$ & $10(10 \%)$ & $22(22 \%)$ & $16(16 \%)$ & $30(30 \%)$ & $60(60 \%)$ & $40(40 \%)$ \\
\hline Total $(n=200)$ & $24(12 \%)$ & $39(19.5 \%)$ & $23(11.5 \%)$ & $26(13 \%)$ & $34(17 \%)$ & $20(10 \%)$ & $44(22 \%)$ & $\begin{array}{c}107 \\
(53.5 \%)\end{array}$ & $93(46.5 \%)$ \\
\hline
\end{tabular}

Legend: 1 - CT-CT - begin and end in cervical third; (CT-MT - begin in cervical third and end in middle third; CT-AT - begin in cervical third and end in apical third; MT-MT - begin and end in middle third; MT-AT - begin in middle third and end in apical third; AT-AT - begin and end in apical third; 2 - 1t was considered the occurrence of more than one type of isthmus by each root canal, which explains the difference between the number of isthmuses analyzed with the number of roots; the isthmus were distributed into categories associated thirds of root in function of map-reading strategy in the coronal-apical direction. The ratings observed in the literature were prepared from serial analysis of static and cross sections.

Table 2. Distribution of root canal isthmus in the in vivo assay in function of its location and number of foramens

\begin{tabular}{|c|c|c|c|c|c|c|c|c|c|}
\hline Teeth & CT-CT & CT-MT & CT-AT & MT-MT & MT-AT & AT-AT & No isthmus & 1 foramen & 2 foramen \\
\hline $\begin{array}{l}\text { Maxillary first } \\
\text { molars }(n=50)\end{array}$ & $0(0 \%)$ & $14(28 \%)$ & $8(16 \%)$ & $5(10 \%)$ & $3(6 \%)$ & $2(4 \%)$ & $19(38 \%)$ & $32(64 \%)$ & $18(36 \%)$ \\
\hline $\begin{array}{l}\text { Maxillary } \\
\text { second molars }(n=50)\end{array}$ & $4(8 \%)$ & $5(10 \%)$ & $8(16 \%)$ & $5(10 \%)$ & $6(12 \%)$ & $4(8 \%)$ & $19(38 \%)$ & $38(76 \%)$ & $12(24 \%)$ \\
\hline $\begin{array}{l}\text { Mandibular } \\
\text { first molars }(n=50)\end{array}$ & $5(10 \%)$ & $2(4 \%)$ & $6(12 \%)$ & $0(0 \%)$ & $7(14 \%)$ & $17(34 \%)$ & $16(32 \%)$ & $24(48 \%)$ & $26(52 \%)$ \\
\hline $\begin{array}{l}\text { Mandibular second } \\
\text { molars }(n=50)\end{array}$ & $8(16 \%)$ & $7(14 \%)$ & $7(14 \%)$ & $2(4 \%)$ & $10(20 \%)$ & $9(18 \%)$ & $12(24 \%)$ & $38(76 \%)$ & $12(24 \%)$ \\
\hline Total $(n=200)$ & $17(8.5 \%)$ & $28(14 \%)$ & $29(14.5 \%)$ & $12(6 \%)$ & $26(13 \%)$ & $32(16 \%)$ & $66(33 \%)$ & $132(66 \%)$ & $68(34 \%)$ \\
\hline
\end{tabular}

Legend: 1 - CT-CT - begin and end in cervical third; (CT-MT - begin in cervical third and end in middle third; CT-AT - begin in cervical third and end in apical third; MT-MT - begin and end in middle third; MT-AT - begin in middle third and end in apical third; AT-AT - begin and end in apical third; 2 - It was considered the occurrence of more than one type of isthmus by each root canal, which explains the difference between the number of isthmuses analyzed with the number of roots; the isthmus were distributed into categories associated thirds of root in function of map-reading strategy in the coronal-apical direction. The ratings observed in the literature were prepared from serial analysis of static and cross sections. 
analyzed (maxillary and mandibular), and all root canal thirds (Tables 1 and 2). Considering the longitudinal mapreading strategy from pulp orifice to the apical third, the aim was to detect and evaluate the frequency of isthmus through CBCT. It was not objective of the study to classify isthmus in each root canal third, however, in the axial planes of CBCT images were detected various forms of isthmus, as previously described (5-7).

Baratto-Filho et al. (16) investigated internal morphology of maxillary first molars by different models, including CBCT analysis (54 maxillary first molars). CBCT results showed 2,4 , and 5 root canals in 1.85\%,37.05\%, and $1.85 \%$ of the teeth, respectively. When present, additional canals showed 1 foramen in $90.90 \%$ of the teeth studied. Operating microscope and CBCT have been important for locating and identifying root canals, and CBCT can be used as a good method for initial identification of maxillary first molar internal morphology. Michetti et al. (22) evaluated the potential of the Kodak 9000 3D CBCT by comparing the cone beam two-dimensional reconstructions with root canal contours obtained by histologic sections viewed under an optical microscope. The results showed a highperformance imaging tool with the complexity of root canals

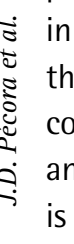
ising as a complementary radiologic examination, still needs further assessment, notably concerning its capacity to reconstruct canal anatomy in vivo. Zhu et al. (19) verified the difference of the incidence and type of
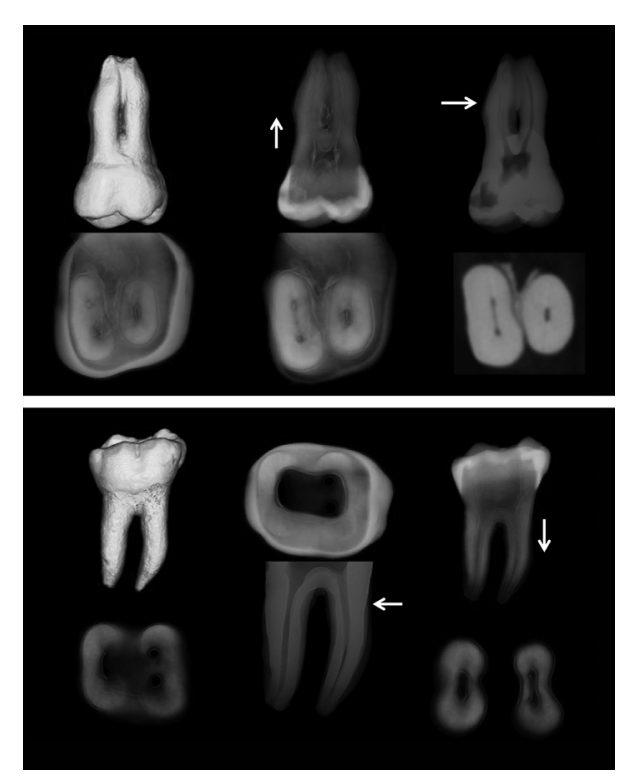

Figure 1. СBCT images shows coronal and axial slices, and 3D reconstructions, of isthmus in maxillary and mandibular molars from ex vivo images. root canal isthmus in maxillary first premolars with single root and two canals before and after instrumentation using $\mathrm{CBCT}$, and investigated the application and effect of $\mathrm{CBCT}$ in analysis of root canal isthmus. The incidence of isthmus was different at each $1 \mathrm{~mm}$ level within apical 0-6 $\mathrm{mm}$ in maxillary first premolar with single root and two canals before and after instrumentation, which was lowest at apical $1 \mathrm{~mm}$ and highest at apical $6 \mathrm{~mm}$; the proportion of partial isthmus was significantly higher than complete isthmus. After instrumentation, the incidence of isthmus in apical 0-6 mm decreased, but the proportion of complete isthmus increased. The difference of root canal isthmus structure before and after instrumentation can be defined accurately with CBCT.

In the present study, СВCT images constitute a precise method to detect root isthmus. These results are in agreement with those of previous studies $(16,19,22)$. In clinical conditions from endodontically treated teeth associated with apical periodontitis (Figs. 3-5), periapical radiography show limited ability to visualize the isthmus area; however, CBCT images detected with a high precision the root isthmus within the filling material.

$\mu \mathrm{CT}$ is another method used to investigate the isthmus area $(17-21,23,24)$. Mannocci et al. (20) used $\mu \mathrm{CT}$ to evaluate the prevalence of root canal isthmuses in the apical 5 $\mathrm{mm}$ of the mesial root of 20 extracted mandibular first molars. The percentage of sections showing isthmuses ranged from 17.25 to $50.25 \%$ in the apical $5 \mathrm{~mm}$ of the root canals. Isthmuses were present in the vast majority of roots observed. Fan et al. (18) verified isthmuses in the mesial roots of 126 first and second mandibular molars using $\mu \mathrm{CT}$. The incidence of an isthmus in the apical $5 \mathrm{~mm}$ of the mesial roots was (107) 85\%. The first molar had more isthmuses with separate type and mixed type, whereas
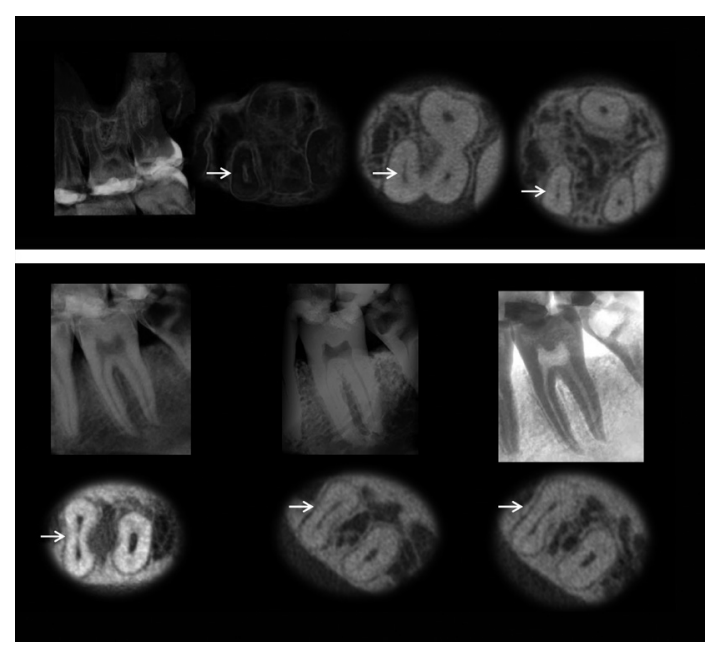

Figure 2. СВСT images shows coronal and axial slices, and 3D reconstructions, of isthmus in maxillary and mandibular molars from in vivo images. 
second molar had more isthmuses with sheet connections. Gu et al. (17) analyzed the prevalence and configuration of the isthmuses in the apical $6 \mathrm{~mm}$ of the mesial and distal roots of 36 extracted human teeth (mandibular first molars) by means $\mu \mathrm{CT}$. The mesial roots of human mandibular first molars had a high incidence of isthmus. The isthmus incidence was greatest 4-6 $\mathrm{mm}$ from the apex in human mandibular first molar, with prevalence of 49.5\%-66.1\% and $17.3 \%-17.8 \%$ in mesial and distal roots, respectively.

The results of the present study by using CBCT showed a frequency of root isthmus in apical third of maxillary molars (mesiobuccal roots) between 4\% (ex vivo) and 6\% (in vivo); and mandibular molars (mesial roots) between 16\% (ex vivo) and 26\% (in vivo).

Considering the association between the evaluations in ex vivo and in vivo, it was verified a frequency of $48 \%$ and $45 \%$ of root isthmuses in mandibular molars which has begun in middle third and ended in apical third. The isthmus
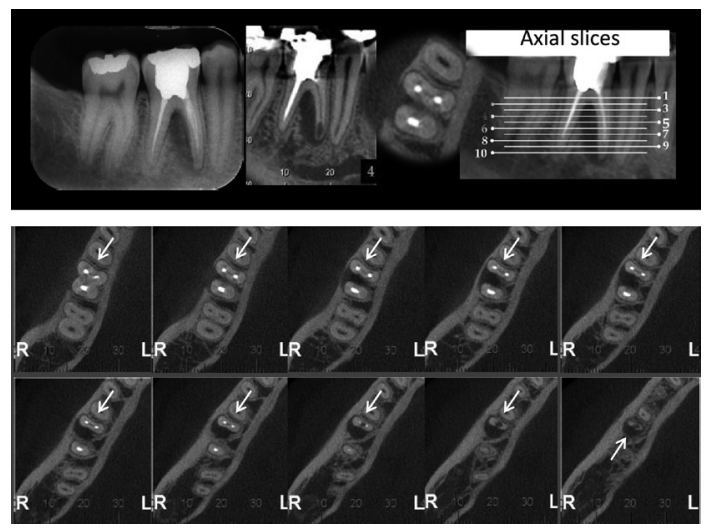

Figure 3. Periapical and СВСТ images a of mandibular right molar associated with root canal treatment and apical periodontitis. The longitudinal map-reading highlights isthmus areas without preparation and filling.
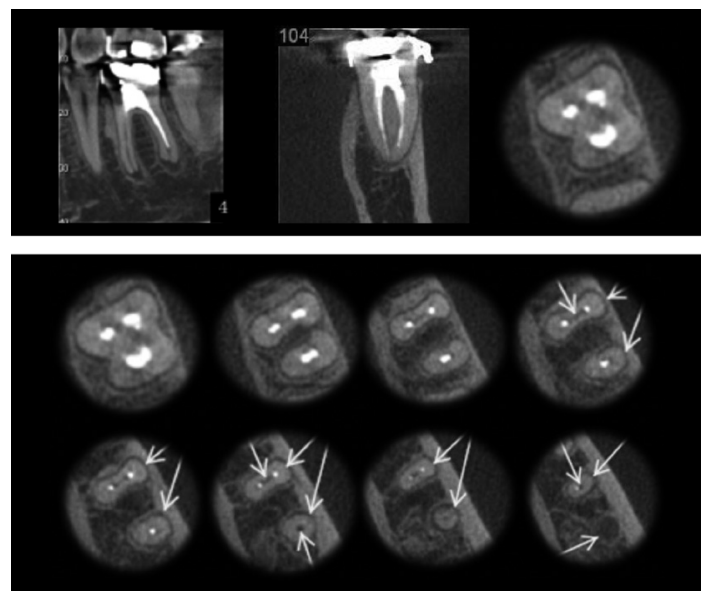

Figure 4. СBCT images of mandibular molar associated with root canal treatment and apical periodontitis. The longitudinal map-reading highlights isthmus areas without preparation and filling. in maxillary molars showed a frequency of 32\% (ex vivo) and 25\% (in vivo). In first and second maxillary molars (in vivo), the isthmuses that began in middle third and ended in the apical third were $20 \%$ and $30 \%$, respectively. In mandibular first and second molars, in the same areas, the frequency was $48 \%$ and $42 \%$, respectively (Tables 1 and 2 ). Weller et al. (5) observed that the prevalence of complete isthmus in the mesiobuccal roots of the maxillary first molars was $5.0 \%$ to $14.8 \%$ (1-6mm of level from apex), and partial isthmus was 23.1 to $88 \%$. Jung et al. (7) found a lower prevalence of partial isthmus (2.6-15.8\%), while Mannocci et al. (20) found a higher frequency of isthmus at $3 \mathrm{~mm}$ (50.25\%) of level from apex than $1 \mathrm{~mm}$ (17.24\%).

When the isthmus begins in cervical third, it is more easy the access by cervical pre-flaring, mechanical action of rotary instruments or ultrasound. In clinical situations with root isthmus which has begun in middle third and end in apical third or when begin and end in apical third, the challenge is the access into these areas.

The clinical implication of this finding involves the difficulty of sanitization, mechanical action to disruption of bacterial biofilms or cleaning of these inaccessible areas. Thus, a rigorous strategy of irrigation and intracanal dressing for better bacterial control should be recommended.

Jung et al. (7) reported that if the root-end preparation only includes the main root canal, bacteria and the other harmful irritants from an isthmus or from an accessory root canal may gain access to the periradicular tissue via the poorly filled root canal system. This would negatively affect the surgical endodontic treatment outcomes.

The differences between the frequencies of isthmus found in this study and others may be explained by some aspects: differences in the methodologies used, the sample
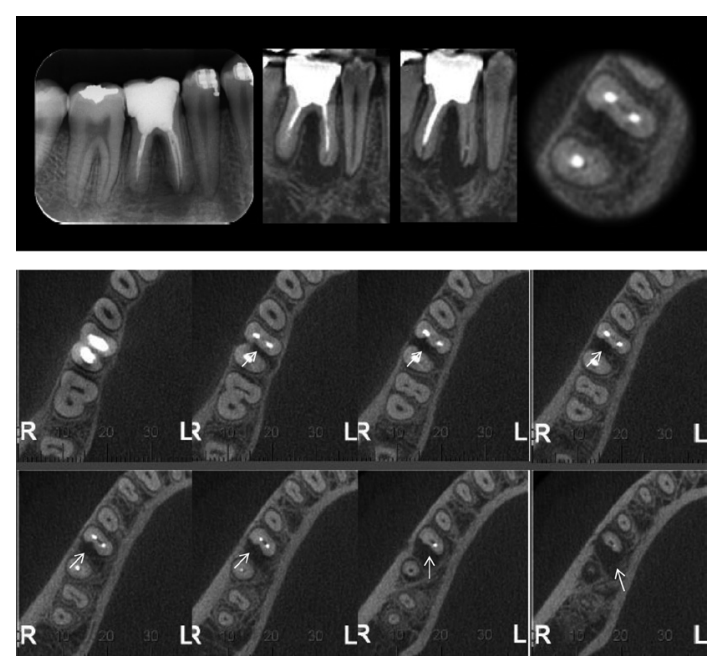

Figure 5. Periapical and CBCT images of mandibular molar endodontically treated associated with apical periodontitis. The longitudinal mapreading highlights isthmus areas without preparation and filling. 
size, the definition of isthmus and the differences in classifications, the age of the teeth (ex vivo study - most do not know the age of the teeth nor the gender of the patients; in vivo study - age and gender can be controlled); calcified teeth and others. In the present study, the goal did not relate to the fourth root canal with the number of foramina, nor the incomplete or complete isthmuses. Although the method used allowed viewing different planes of the tooth anatomical structure, the focus of attention was restricted to detection accuracy and frequency of isthmus using a navigation tool.

The agent of the cause of the RCT failure may not be the exclusive responsibility of the root isthmus. The difficulty of access favors bacteria refuge in this complex area of the root canal, meaning a risk factor for RCT failure and surgical endodontic procedures. Future studies in search of new strategies for sanitization, the implications of RCT failures and analysis of new technologies such as CBCT and $\mu \mathrm{CT}$ are required.

In this study, the isthmuses were detected in all thirds of the root canals. The frequency of isthmuses was high in both methods and tooth groups. The map-reading dynamics in CBCT images is precise to detect the localization of isthmus.

\section{Acknowledgements}

This study was supported in part by grants from the National Council for Scientific and Technological Development (CNPq \#306394/2011-1 to C.E.).

\section{Resumo}

0 objetivo deste estudo foi detectar a presença de istmos em molares superiores e inferiores, e avaliar a frequência usando dinâmica de navegação em imagens de tomografia computadorizada de feixe cônico (TCFC). Duzentos molares superiores e inferiores humanos foram usados em ensaio ex vivo. Uma amostra consecutiva de duzentos molares (superiores e inferiores, primeiros e segundos) foi selecionada a partir de exames de TCFC. Os istmos foram detectados a partir do orifício de entrada da cavidade pulpar em direção ao ápice, de acordo com o início e o fim, nas categorias: 1 . início e término no terço cervical; 2 . início no terço cervical e término no terço médio; 3 . início no terço cervical e término no terço apical; 4. início e fim no terço médio; 5 . início no terço médio e término no terço apical; 6 . início e término no terço apical ; 7. ausência de istmo radicular. Os exames de TCFC foram obtidos em diferentes planos com estratégias de navegação em cortes axiais de $0,5 \mathrm{~mm} / 0.5 \mathrm{~mm}$ de coronal para a direção apical. As frequências de istmo radicular foram analisadas de acordo com o terço da raiz e avaliadas pelo teste do qui-quadrado. 0 nivel de significância estabelecido foi de $5 \%$. A presença de istmo radicular em molares superiores foi de $86 \%$ em ensaio ex vivo e $62 \%$ em ensaio in vivo, enquanto que, em molares inferiores foram observados $70 \%$ em ensaio ex vivo e $72 \%$ em ensaio vivo. A frequência radicular de istmo foi elevada em ambos os modelos de estudo. A dinâmica da estratégia de navegação em imagens de TCFC é precisa para detectar a localização do istmo radicular.

\section{References}

1. Green D. Morphology of the pulp cavity of the permanent teeth. Oral Surg Oral Med Oral Pathol 1955;7:743-759.

2. Pineda $F$, Kuttler $Y$. Mesiodistal and buccolingual roentgenographic investigation of 7,275 root canals. Oral Surg Oral Med Oral Pathol 1972;33:101-110
3. Pécora JD, Woelfel JB, Sousa-Neto MD. Morphologic study of the maxillary molars. Part II. Braz Dent J 1992;3:53-57.

4. Vertucci FJ. Root canal morphology and its relationship to endodontic Procedures. Endod Topics 2005;10:3-29.

5. Weller NR, Niemczyk SP, Kim S. Incidence and position of the canal isthmus. Part 1. Mesiobuccal root of the maxillary first molar. J Endod 1995; 21:380-383.

6. Hsu Y, Kim S. The resected root surface: the issue of canal isthmuses. Dent Clin N Am 1997: 3: 529-540.

7. Jung $I-Y$, Seo $M-A$, Fouad $A F$, Spångberg LSW, Lee S-J, et al.. Apical Anatomy in mesial and mesiobuccal roots of permanent first molars. J Endod 2005;31:536-538.

8. Teixeira FB, Sano CL, Gomes BPFA, Zaia AA, Ferraz CCR, Souza-Fiho FJ. A preliminary in vitro study of the incidence and position of the root canal isthmus in maxillary and mandibular first molars. Int Endod J 2003;36:276-280.

9. Von Arx T. Frequency and type of canal isthmuses in first molars detected by endoscopic inspection during periradicular surgery. Int Endod J 2005;38:160-168.

10. Degerness RA, Bowles WR. Dimension, anatomy and morphology of the mesiobuccal root canal system in maxillary molars. J Endod 2010;36:985-989.

11. Estrela C, Holland R, Estrela CRA, Alencar AHG, Sousa-Neto MD, Pécora JD. Characterization of successful root canal treatment. Braz Dent $J$ 2014 (in press).

12. Nair PNR, Henry $S$, Cano V, Vera J. Microbial status of apical root canal system of human mandibular first molars with primary apical periodontitis after one-visit-endodontic treatment. Oral Surg Oral Med Oral Pathol Oral Radiol Endod 2005;99:231-252.

13. Bender IB. Factors influencing the radiographic appearance of bony lesions. J Endod 1982;8:161-170.

14. Estrela C, Bueno MR, Leles CR, Azevedo B, Azevedo JR. Accuracy of cone beam computed tomography and panoramic and periapical radiography for detection of apical periodontitis. J Endod 2008;34:273-279.

15. Durack $\mathrm{C}$, Patel $\mathrm{S}$. Cone beam computed tomography in endodontics. Braz Dent J 2012;23:179-191.

16. Baratto-Filho F, Zaitter $S$, Haragushiku GA, de Campos EA, Abuabara A, Correr GM. Analysis of the internal anatomy of maxillary first molars by using different methods. J Endod 2009;35:337-342.

17. Gu L-S, Ling J-Q, Huang X-Y, Wei X, Xu Q. A micro-computed tomographic study of the isthmus in the root canal system of mandibular first molar. Chin J Stomatol 2009;44:11-14.

18. Fan B, Pan Y, Gao Y, Fang F, Wu Q, Gutmann JL. Three-dimensional morphologic analysis of isthmuses in the mesial roots of mandibular molars. J Endod 2010;36:1866-1869.

19. Zhu LN, Qian WH, Hong J. A cone-beam computed tomography study of changes in canal isthmus of maxillary first premolars before and after instrumentation. Shanghai Kou Qiang Yi Xue 2013;22:41-45.

20. Mannocci F, Peru M, Sherriff M, Cook R, Pitt Ford TR. The isthmuses of the mesial root of mandibular molars: a micro-computed tomographic study. Int Endod J 2005;38:558-563.

21. Seo D-G, Gu Y, Yi Y-A, Lee S-J, Jeong J-S, Lee Y, et al.. A biometric study of $\mathrm{C}$-shaped root canal systems in mandibular second molars using cone-beam computed tomography. Int Endod J 2012;45:807-814.

22. Michetti J, Maret D, Mallet J-P, Diemer F. Validation of cone beam computed tomography as a tool to explore root canal anatomy. J Endod 2010;36:1187-1190.

23. Tachibana H, Matsumoto K. Applicability of X-ray computerized tomography in endodontics. Endod Dent Traumatol 1990;6:16-20.

24. Versiani MA, Pécora JD, Sousa-Neto MD. Root canal morphology of four-rooted maxillary second molars: a micro computed tomography study. J Endod 2012;38:977-982.

25. Bueno MR, Estrela C, Figueiredo JAP, Azevedo BC. Map-reading strategy to diagnose root perforations near metallic intracanal posts by using cone beam computed tomography. J Endod 2011;37:85-90. 